\title{
Student perceptions of their autonomy at University
}

\author{
D. C. Henri ${ }^{1}$ • L. J. Morrell ${ }^{1}$ - G. W. Scott ${ }^{1}$
}

Published online: 6 June 2017

(C) The Author(s) 2017. This article is an open access publication

\begin{abstract}
Learner autonomy is a primary learning outcome of Higher Education in many countries. However, empirical evaluation of how student autonomy progresses during undergraduate degrees is limited. We surveyed a total of 636 students' self-perceived autonomy during a period of two academic years using the Autonomous Learning Scale. Our analysis suggests that students do not perceive themselves as being any more autonomous as they progress through University. Given the relativity of self-perception metrics, we suggest that our results evince a "red queen" effect. In essence, as course expectations increase with each year, each student's self-perceived autonomy relative to their ideal remains constant; we term this the "moving goalpost" hypothesis. This article corroborates pedagogical literature suggesting that providing students with opportunities to act autonomously and develop confidence is key to developing graduates who have the independence that they need in order to be successful in the workplace.
\end{abstract}

Keywords Autonomy·Self-efficacy · Independent learning $\cdot$ Employability· Student-led learning $\cdot$ Autonomous Learning Scale

\section{Introduction}

In a broad sense, learner autonomy has been positively linked to successful learning experiences and life satisfaction in Europe, the USA and East Asia (e.g. Chemers et al. 2001; Ghanizadeh 2016; Levesque et al. 2004; Littlewood 1999; Vansteenkiste et al. 2005). In the UK context, developing autonomy is an integral "learning outcome" of most university courses, and final-year studies often culminate in student-led research projects, which may be empirical or literature-based. Learning autonomy is also an expectation of UK graduates by UK employers (CBI 2009; Smyth et al. 2016). Despite this, there is significant variation in

D. C. Henri

d.henri@hull.ac.uk

1 School of Biological, Biomedical and Environmental Sciences, University of Hull, Kingston upon Hull HU6 7RX, UK 
what constitutes learner autonomy. Definitions of learner autonomy generally include a number of key themes: responsibility or ownership of outcomes (internal locus of control); confidence in skills or ability to achieve (self-efficacy); engagement with student-led learning (self-regulation) (Chan 2001; Fazey and Fazey 2001; Macaskill and Taylor 2010; Macaskill and Denovan 2013); and, the "surface" vs. "deep" approach, where autonomous students independently attempt to expand their knowledge base instead of focusing on prescribed material (Thomas et al. 2015). These themes align with the commonly held view of university teachers that university students "should" differ from school pupils by actively pursuing their own education agenda within the higher education environment (Lowe and Cook 2003; Scott et al. 2015; Thomas et al. 2015). Two schools of thought exist on whether students do indeed develop autonomy over the course of their university degrees: one argues that autonomy is a fixed trait of individuals that changes little over time, while the other suggests it can be developed.

The perception of some university teachers is that student autonomy, rather than developing over time, is idiosyncratic (Scott et al. 2015) and that universities are not facilitating the development of autonomy. Small-scale, self-perception studies support this "fixed-attribute" scenario because they do not find patterns in autonomy across years or according to whether a student is "mature" (aged over 21 when starting the course) or not (Fazey and Fazey 2001; Scott et al. 2015). While mature students, female students and later-stage students self-report spending more time on "independent study", which reflects ownership of learning and selfmanagement, much of this corresponds to rereading lecture notes (Thomas et al. 2015), which does not reflect the "deep", independent approach imagined by many academics when they consider an autonomous student. Variation in autonomy between individual students is highlighted by the fact that levels of autonomy and engagement of first-year undergraduates tend to reflect learning approaches taken during secondary education (Lowe and Cook 2003). In addition, increasing numbers of students view themselves as "customers", which may be promoting a dependent, surface approach to their higher education (Budd 2016; Naidoo and Jamieson 2005). Indeed, some would suggest that attending university is a culturally acceptable method of delaying the onset of independence (Furedi 2003).

However, there is evidence that student autonomy can be developed by relevant "events". For example, student self-efficacy (an aspect of autonomy) responds positively to experiences that confirm that the student is capable of working autonomously, such as work or research placements (Willison et al. 2016; Qenani et al. 2014). Many students report that their interaction with literature resources and learning independence, potential measures of selfmanagement, have increased as a result of studying at University (Thomas et al. 2015). Finalyear students are also more likely to engage with feedback, suggesting an increased ownership of their progression and learning (Brown 2007). A student's ability to self-assess can be developed through iterative attempts at assessment, where the ability to self-assess represents a transition from dependent tutor-led learning to independent lifelong learning (Nicol and Macfarlane-Dick 2006; Morrell 2014). Finally, by reinforcing perceptions of students' positive autonomy-related traits through targeted workshops, one can improve both student selfconfidence and autonomous learning traits (Macaskill and Denovan 2013). These studies and recent student surveys suggest that many key traits that underlie autonomy may be developed by independent, student-led learning practices (NSSE 2016; Connell et al. 2016).

Students' perceptions of their own abilities are also linked to their learner autonomy. Students with greater self-efficacy are more likely to view their own capabilities as being changeable, whereas those with low self-efficacy view intelligence as a fixed personal attribute 
(Komarraju and Nadler 2013), and the level of autonomy exhibited by a student reflects selfconfidence in their decisions and abilities (Bandura 1989; Bandura 2012; Fazey and Fazey 2001). While students report spending more time on self-directed study as they move through their degree programmes (Thomas et al. 2015), there is little evidence to suggest that they perceive themselves as more autonomous learners (Scott et al. 2015). If the development of autonomy is a key aim of university education and expectation of graduate employers, then it is essential that students are able to perceive (and articulate) the development of their autonomy over time. The primary aim of our study is to establish how patterns of perceived autonomy develop as a result of the university experience through the exploration of a case study carried out in a mainstream, second-wave civic UK university established in 1954. Using the contrasting hypotheses that (a) self-perceived student autonomy is a fixed trait and (b) selfperceived student autonomy develops over time as a framework for our study, we use the "Autonomous Learning Scale" developed by Macaskill and Taylor (2010) to survey 625 individual students who participated at least once in the survey.

\section{Methods}

\section{The Autonomous Learning Scale}

The Autonomous Learning Scale (ALS) (developed by Macaskill and Taylor 2010) presents a simple method of quantifying student autonomy, which requires students to answer a questionnaire consisting of only 12 questions with respondents rating themselves on a 5-point Likert scale. For analysis, the responses are always weighted such that a higher value corresponds to greater autonomy. Its usefulness and relatability to student autonomy, self-efficacy and selfesteem have been established previously (Macaskill and Taylor 2010; Macaskill and Denovan 2013; Scott et al. 2015). The ease of use makes the ALS highly suitable to a large-scale study surveying a diverse student body to observe inter-individual observations as well as withinindividual observations across time. We have altered the ALS questions marginally such that they are not always positively worded, for details see Scott et al. (2015).

Paper-based questionnaires were completed at the beginning of formal lecture classes by students enrolled in BSc programmes within a School of Biomedical, Biological and Environmental Sciences at three time points (the beginning of semesters 1 and 2 of 2015 and semester 1 of 2016). The results of this study are drawn from 825 fully completed surveys, from 635 students; 34 students took part at all three time points, 142 took part at two time points and the remainder only once. We have performed two separate analyses: one from all 825 surveys and another from the 74 participants who completed surveys at the beginning of semester one in both 2015 and 2016. The first of these provides a detailed evaluation of key factors thought to be related to learner autonomy (gender identity, level of study and maturity) supported by a large dataset, while the second focuses on following changes in individual ALS score over time. Table 1 provides the student demographics for completed surveys.

\section{Statistics}

To create a dependent variable from the questionnaire, we have used the average score of each student across the 12 questions; average scores have been used instead of sum scores as it makes data more robust to outliers within the questions. A Linear Mixed-Effect (LME) model, 
Table 1 Demographics of individual students that took part in the study across different levels of engagement; each student only counts once for each column

\begin{tabular}{lllll}
\hline & & $\begin{array}{l}\text { At least one } \\
\text { questionnaire }\end{array}$ & $\begin{array}{l}\text { All three } \\
\text { questionnaires }\end{array}$ & $\begin{array}{l}\text { Questionnaires in semester 1 in } \\
2015 \& 2016\end{array}$ \\
\hline Gender & Male & 260 & 16 & 35 \\
\multirow{2}{*}{ Age at start of } & Female & 375 & 18 & 39 \\
programme & $<22$ & 511 & 28 & 63 \\
& $22-25$ & 75 & 5 & 9 \\
Level of study at first & Foundation & 120 & 1 & 2 \\
survey & 1st UG & 234 & 9 & 11 \\
& 2nd UG & 166 & 12 & 27 \\
\multirow{2}{*}{ Total } & 3rd UG & 115 & 13 & 36 \\
\hline
\end{tabular}

with random intercept structure, was used to test for associations between ALS score and student gender, age at start of course and level of study at time of survey. In the longitudinal analysis, age at start of course and gender were not included as they left the model overspecified. In both analyses, student identity was used as a random effect to avoid pseudoreplication and time point was included as a random effect to control for cohort effects; a repeated-measures ANOVA would not have been possible here because we did not have surveys from all individuals at all time points. LME analysis was performed using R statistical package for Windows (R Core Team 2014) and the lmer function in the lme4 package (Bates 2010). Initial explorations to check GLMM assumptions were performed following guidelines in Zuur et al. (2010); revealing that data were normally distributed and the ratio of errors between groups was less than 4 . The Minimum Adequate Model was established via loglikelihood ratio model simplification using Maximum Likelihood approximation, for which $X^{2}$ results indicating significance are reported.

\section{Internal consistency reliability}

Due to the recent criticism of the Cronbach's alpha as a measure of questionnaire reliability, we have calculated omega coefficients for the test as a whole (Dunn et al. 2014). Given the large number of surveys ( $n=825$ ), we feel confident that the dataset is sufficiently large for these coefficient calculations to be accurate (minimum $n=50$; Ercan et al. 2007). Coefficient omega for the whole questionnaire $=0.67,95 \%$ CI $[0.63,0.7]$.

\section{Results}

\section{All questionnaires}

We performed Linear Mixed-Effect modelling to look for differences in learner autonomy in all 825 completed questionnaires, focusing on differences between level of study at time of questionnaire, age at start of the course and student gender. Analyses suggest that only student gender was significantly associated with average ALS score $\left(X^{2}{ }_{1}=6.20, P=0.01\right)$. Male students had a higher average ALS (indicating higher levels of autonomy) than female students. However, average ALS was not significantly associated with starting age 
$\left(X_{2}^{2}=5.63, P=0.06\right)$ or current level of study $\left(X^{2}{ }_{3}=2.60, P=0.46\right)$. There were no significant interactions between any of these factors. Table 2 provides means and standard errors from analyses.

\section{Longitudinal study}

We also performed LME analyses on the surveys completed by the 74 students who participated in semester one in both 2015 and 2016. Our analysis looked for differences in individual learner autonomy between years and average differences across level of study. Analyses suggest that individual ALS scores did not exhibit any significantly consistent positive or negative changes between 2015 and $2016\left(X^{2}{ }_{4}=2.52, P=0.64\right)$, and there was no interaction between change between years and level of study $\left(X^{2}{ }_{1}=0.143, P=0.71\right)$ (Fig. 1). Furthermore, there was no significant difference in average ALS scores across level of study $\left(X_{3}^{2}=2.38, P=0.5\right)$.

\section{Discussion}

Our study suggests that, on average, students' perception of their autonomy does not increase as they progress through their courses: there is no overall increase in autonomy with level of study, and individual students did not report a consistently upward trend in autonomy between the two time points used in our study (Table $2 \&$ Fig. 1). We find no effect of student maturity, suggesting mature students (aged over 21 at the start of their programme) do not perceive themselves as more autonomous than other students, but we do find, in line with other studies relying on self-reported values of capability (Ainscough et al. 2016; Fazey and Fazey 2001; Qenani et al. 2014), that female students perceive themselves as less autonomous than male students.

Our finding that students do not perceive themselves as more autonomous as they progress through their course contrasts with previous work suggesting that at least two aspects of learner autonomy, self-regulation and depth of learning, do increase over time, as final-year students spend more time studying than first-year students and more time pursuing deep learning than second-year students (Thomas et al. 2015). Together, this suggests that although autonomy itself increases, student perception of that autonomy does not, although no study has yet directly linked the two. While the ALS questionnaire relies on subjective self-perception, Thomas et al. (2015) used objective learner diaries. Self-perception is relative-for example, a

Table 2 Means (s.e.) of average ALS score across all 825 surveys for the factors gender, age at start of programme and level of study

\begin{tabular}{llr}
\hline Gender $^{*}$ & Male & $2.31(0.02)$ \\
& Female & $2.23(0.02)$ \\
Age at start of programme & $<22$ & $2.27(0.02)$ \\
& $22-25$ & $2.18(0.05)$ \\
Level of study & $>25$ & $2.30(0.07)$ \\
& Foundation & $2.24(0.04)$ \\
& 1 st UG & $2.25(0.03)$ \\
& 2nd UG & $2.30(0.03)$ \\
& 3rd UG & $2.29(0.03)$ \\
\hline
\end{tabular}

\footnotetext{
*Factor group averages are significantly different in LME analysis at the $P<0.05$ level.
} 


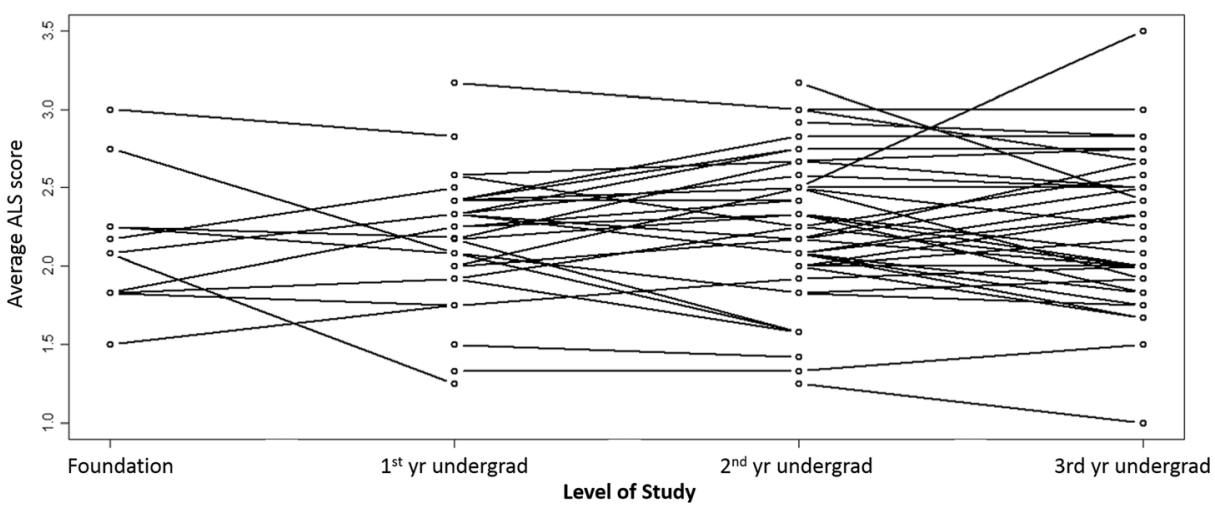

Fig. 1 Longitudinal responses of average ALS score for each individual surveyed in semester one of both 2015 and 2016. Individual progression between the two years is denoted by a single line

student's self-efficacy is often tied to their on-going grades (Ainscough et al. 2016). Similarly, confidence, which mediates self-perception of capability, is a function of a student's perceived discrepancy between where they are and where they perceive that they "ought to be" (Fazey and Fazey 2001). Self-efficacy, often considered a first step in the development of autonomy (Fazey and Fazey 2001; Komarraju and Nadler 2013), is also influenced positively in the short-term by positive feedback and negatively by negative feedback, even when study habits have not changed (Bandura 2012; Macaskill and Denovan 2013). Together, this suggests that a student's perception of his or her own autonomous capabilities is a function of much more than just their actual autonomy. Pairing the ALS questionnaire with other objective measures of autonomy would go some way towards improving our understanding of the interaction between perceived and actual autonomy.

If academic environment, such as feedback or the provision of "difficult" tasks (Sitzmann and Ely 2011), impacts on self-perception, then our results may illustrate a "red queen" effect (Carroll 1917; van Valen 1973), where an individual "runs" as fast as they can just to stay in the same place (Carroll 1917; van Valen 1973). As teacher expectations of autonomy increase over the course of a degree programme (Scott et al. 2015), the discrepancy between student perceptions of their capability and where they "ought to be" remains constant, driving a constancy in perception of autonomy (Fazey and Fazey 2001; Vancouver and Kendall 2006). Essentially, students assess their skills based on how they "feel" they are doing, rather than on how they are actually doing. This interpretation is supported by empirical evidence that "hope agency" (the belief that goals are attainable) is one of the strongest predictors of individual autonomous behaviour as measured by the ALS (Macaskill and Denovan 2013), and the fact that the belief that a goal is attainable is tied to self-efficacy and the confidence to learn in an autonomous manner (Bandura 1989). The relativity of self-perception combined with the increasing demands of higher education may drive a constant, or even decreasing, self-perception of autonomy in some students.

We call the idea that students perceive themselves as being at the same level throughout their course because the course becomes more demanding the "moving goalpost model" (Fig. 2). This model may explain why some studies of self-perceived capability, particularly those that focus on non-specific skills (such as general self-efficacy and autonomy), have found no relationship between level of study and capability (Ekici et al. 2012; Scott et al. 2015). Students in higher education are generally not very good at self-reflection and self- 
Fig. 2 Hypothetical graph illustrating the "moving goalpost" hypothesis. In essence, student autonomy is developing, but because there is a consistent gap between where students perceive themselves and where they need to be to achieve, their self-efficacy remains constant; essentially, perpetuating a "red queen" effect where continued effort is required to maintain the same level of selfefficacy relative to external pressure

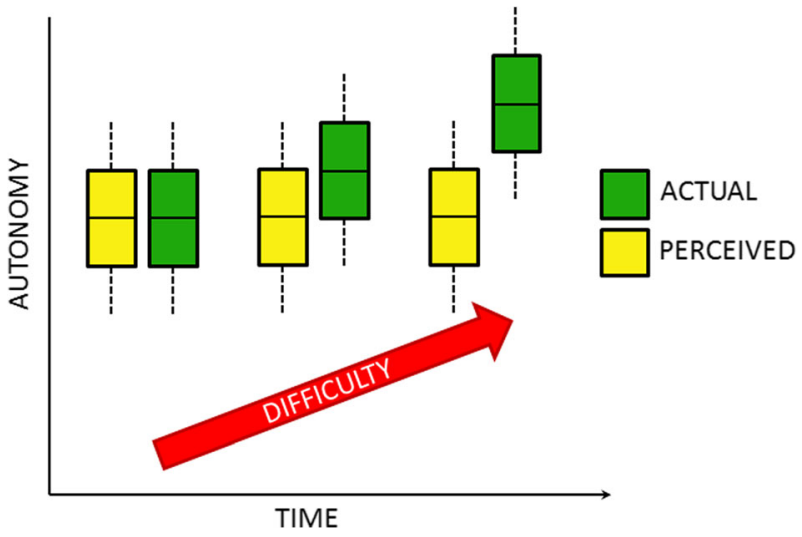

assessment (Boud and Falchikov 1989; Karnilowicz 2012; Randles and Overton 2015), but they are often well aware of their development in specific skills that can be expressly taught (Ainscough et al. 2016). A lack of perceived progress may be a barrier to developing all aspects of learner autonomy as they are difficult to monitor expressly (Fazey and Fazey 2001; Macaskill and Denovan 2013). This may be a particular problem for female students, who have a tendency to report a greater discrepancy between their own capabilities and what they think is required (Fazey and Fazey 2001), which could lead to the lower self-perception of autonomy reported here.

Mature students did not perceive themselves as either more or less autonomous than other students, which again may reflect the impact of self-perception. Academic staff view mature students in one of two ways: highly motivated, "here-by-choice" students with high levels of engagement, and those that lack confidence in their academic skills and perceive younger students as being "cleverer" or more used to studying (Scott et al. 2015). We might predict the first group to have a high perception of their autonomy, as motivation and engagement are a significant component of self-management and autonomy (Harackiewicz et al. 2008; Krapp and Prenzel 2011), while the second group may have lower perception as their self-doubt acts as a barrier to autonomy (Sitzmann and Ely 2011). This reflects previous work which does not provide a clear picture of the relationship between student age and learning autonomy (Derrick et al. 2007) and again highlights the need for studies measuring both perceived and actual learner autonomy, together with other factors such as self-confidence, motivation and engagement.

Our study highlights the need to provide students with opportunities to be autonomous (which can be limited in higher education; Fazey and Fazey 2001; Thomas et al. 2015; Willison et al. 2016), but also the need for students to recognise their autonomy (Fazey and Fazey 2001; Macaskill and Denovan 2013). We cannot currently distinguish whether the lack of change across levels of study supports our moving goalpost model or indicates a lack of student development. Building self-perception is an integral aspect of student satisfaction; students who do not feel they have progressed are unlikely to think favourably of the course (Spooren et al. 2013), which could be problematic with the global pattern of increasing reliance on satisfaction as a metric of course value (Naidoo and Jamieson 2005). Positive self-perception of capabilities also reduces drop-out rates and increases graduate prospects (Bandura 1989; Bandura 2012; Komarraju and Nadler 2013; Qenani et al. 2014; Yeo and Neal 
2006). The integration of self-reflective exercises might be particularly useful in this respect (Boud 2013); one study in particular promoted learner autonomy through the use of a continuous reflective diary (Yang 1998). Promoting self-reflection in this context may have additional benefits on other transferable skills such as critical thinking (Ghanizadeh 2016). Alternatively, a shift towards authentic learning experiences, such as placement-based learning experiences and independent research projects, can help build some key components of learner autonomy such as self-efficacy and self-regulation (Smyth et al. 2016; Tytler 1992). Tracking both perceived and actual autonomy of students over the course of their programme could highlight both opportunities for the development of autonomy within programmes (such as identifying course components which boost either autonomy, perception of autonomy or both) and enhance student perception of their autonomy.

Acknowledgements The authors would like to thank the support of the University of Hull's Bioscience Education Research group for their support in our research. The Autonomous Learner Project was funded by the University of Hull's Innovations in Student Learning Scheme. Thanks to Luke Rothery for his support in typing up the questionnaires.

\section{Compliance with ethical standards}

Conflict of interest The authors declare that they have no conflict of interest related to the publication of this work.

Ethical approval and informed consent Ethical approval for this study was obtained from the relevant university ethics committee. All participants were volunteers briefed prior to filling in the questionnaire, and all provided informed consent. All students were free to withdraw their data at any time. Student numbers have been used to preserve anonymity within the dataset.

Open Access This article is distributed under the terms of the Creative Commons Attribution 4.0 International License (http://creativecommons.org/licenses/by/4.0/), which permits unrestricted use, distribution, and reproduction in any medium, provided you give appropriate credit to the original author(s) and the source, provide a link to the Creative Commons license, and indicate if changes were made.

\section{References}

Ainscough, L., Foulis, E., Colthorpe, K., Zimbardi, K., Robertson-Dean, M., Chunduri, P., \& Lluka, L. (2016). Changes in biology self-efficacy during a first-year university course. CBE-Life Sciences Education, 15(2), 19.

Bandura, A. (1989). Regulation of cognitive processes through perceived self-efficacy. Developmental Psychology, 25(5), 729.

Bandura, A. (2012). On the functional properties of perceived self-efficacy revisited. Journal of Management, $38(1), 9-44$.

Bates, D. M. (2010) lme4: Mixed-effects modeling with R. Springer. URL http://lme4.0.r-forge.rproject. org/lMMwR/lrgprt.pdf.

Boud, D. (2013). Enhancing learning through self-assessment. Routledge. URL https://books.google.co. $\mathrm{uk} /$ books?id=_fWOAQAAQBAJ\&dq=Enhancing+learning+through+selfassessment \&lr=\&source=gbs navlinks s.

Boud, D., \& Falchikov, N. (1989). Quantitative studies of student self-assessment in higher education: a critical analysis of findings. Higher Education, 18(5), 529-549.

Brown, J. (2007). Feedback: the student perspective. Research in Post-Compulsory Education, 12(1), 33-51.

Budd, R. (2016). Undergraduate orientations towards higher education in Germany and England: problematizing the notion of 'student as customer'. Higher Education, 73(1), 23-37. URL https://link.springer. com/article/10.1007/s10734-015-9977-4. 
Carroll, L. (1917). Through the looking glass: and what Alice found there. Rand McNally.

CBI. (2009). Future fit: preparing graduates for the world of work. London: CBI.

Chan, V. (2001). Readiness for learner autonomy: what do our learners tell us? Teaching in Higher Education, $6(4), 505-518$.

Chemers, M. M., Hu, L. T., \& Garcia, B. F. (2001). Academic self-efficacy and first year college student performance and adjustment. Journal of Educational Psychology, 93(1), 55.

Connell, G. L., Donovan, D. A., \& Chambers, T. G. (2016). Increasing the use of student-centered pedagogies from moderate to high improves student learning and attitudes about biology. CBE-Life Sciences Education, 15(1), 3.

Derrick, M. G., Rovai, A. P., Ponton, M., Confessore, G. J., \& Carr, P. B. (2007). An examination of the relationship of gender, marital status, and prior educational attainment and learner autonomy. Educational Research and Review, 2(1), 1-8.

Dunn, T. J., Baguley, T., \& Brunsden, V. (2014). From alpha to omega: a practical solution to the pervasive problem of internal consistency estimation. British Journal of Psychology, 105(3), 399-412.

Ekici, G., Fettahlığlu, P., \& Sert-Çıbık, A. (2012). Biology self-efficacy beliefs of the students studying in the department of biology and department of biology teaching. International Online Journal of Educational Sciences, 4(1), 39-49.

Ercan, I., Yazici, B., Sigirli, D., Ediz, B., \& Kan, I. (2007). Examining Cronbach alpha, theta, omega reliability coefficients according to sample size. Journal of Modern Applied Statistical Methods, $6(1), 27$.

Fazey, D. M., \& Fazey, J. A. (2001). The potential for autonomy in learning: perceptions of competence, motivation and locus of control in first-year undergraduate students. Studies in Higher Education, 26(3), $345-361$.

Furedi, F. (2003). The children who won't grow up. Spiked essays, 29 URL http://www.spiked-online. com/newsite/article/2775\#.WSgtl2Tyu70.

Ghanizadeh, A. (2016). The interplay between reflective thinking, critical thinking, self-monitoring, and academic achievement in higher education. Higher Education, 1-14. URL https://link.springer. com/article/10.1007/s10734-016-0031-y.

Harackiewicz, J. M., Durik, A. M., Barron, K. E., Linnenbrink-Garcia, L., \& Tauer, J. M. (2008). The role of achievement goals in the development of interest: reciprocal relations between achievement goals, interest, and performance. Journal of Educational Psychology, 100(1), 105.

Karnilowicz, W. (2012). A comparison of self-assessment and tutor assessment of undergraduate psychology students. Social Behavior and Personality: An International Journal, 40(4), 591-604.

Komarraju, M., \& Nadler, D. (2013). Self-efficacy and academic achievement: why do implicit beliefs, goals, and effort regulation matter? Learning and Individual Differences, 25, 67-72.

Krapp, A., \& Prenzel, M. (2011). Research on interest in science: theories, methods, and findings. International Journal of Science Education, 33(1), 27-50.

Levesque, C., Zuehlke, A. N., Stanek, L. R., \& Ryan, R. M. (2004). Autonomy and competence in German and American university students: a comparative study based on self-determination theory. Journal of Educational Psychology, 96(1), 68.

Littlewood, W. (1999). Defining and developing autonomy in East Asian contexts. Applied Linguistics, 20(1), 71-94.

Lowe, H., \& Cook, A. (2003). Mind the gap: are students prepared for higher education? Journal of Further and Higher Education, 27(1), 53-76.

Macaskill, A., \& Denovan, A. (2013). Developing autonomous learning in first year university students using perspectives from positive psychology. Studies in Higher Education, 38(1), 124-142.

Macaskill, A., \& Taylor, E. (2010). The development of a brief measure of learner autonomy in university students. Studies in Higher Education, 35(3), 351-359.

Morrell, L. J. (2014). Use of feed-forward mechanisms in a novel research-led module. Bioscience Education, 22(1), 70-81.

Naidoo, R., \& Jamieson, I. (2005). Empowering participants or corroding learning? Towards a research agenda on the impact of student consumerism in higher education. Journal of Education Policy, 20(3), 267-281.

Nicol, D. J. \& Macfarlane-Dick, D. (2006). Formative assessment and selfregulated learning: A model and seven principles of good feedback practice. Studies in higher education, 31(2), 199-218.

National Survey of Student Engagement. (2016). Engagement insights: survey findings on the quality of undergraduate education - annual results 2016. In RESEARCH, I. U. C. F. P (Ed.), National survey of student engagement. Bloomington, IN: Indiana University Center for Postsecondary Research.

Qenani, E., MacDougall, N., \& Sexton, C. (2014). An empirical study of self-perceived employability: improving the prospects for student employment success in an uncertain environment. Active Learning in Higher Education, 15(3), 199-213. 
R Core Team (2014). R: A language and environment for statistical computing. R Foundation for Statistical Computing, Vienna, Austria. URL http://www.R-project.org/.

Randles, C. A., \& Overton, T. L. (2015). Expert vs. novice: approaches used by chemists when solving openended problems. Chemistry Education Research and Practice, 16(4), 811-823.

Scott, G. W., Furnell, J., Murphy, C. M., \& Goulder, R. (2015). Teacher and student perceptions of the development of learner autonomy; a case study in the biological sciences. Studies in Higher Education, 40(6), 945-956.

Sitzmann, T., \& Ely, K. (2011). A meta-analysis of self-regulated learning in work-related training and educational attainment: what we know and where we need to go. Psychological Bulletin, 137(3), 421.

Smyth, L., Davila, F., Sloan, T., Rykers, E., Backwell, S., \& Jones, S. B. (2016). How science really works: the student experience of research-led education. Higher Education, 1-17. URL https://link.springer. com/article/10.1007/s10734-015-9945-Z.

Spooren, P., Brockx, B., \& Mortelmans, D. (2013). On the validity of student evaluation of teaching the state of the art. Review of Educational Research, 83(4), 598-642.

Thomas, L., Hockings, C., Ottaway, J., \& Jones, R. (2015). Independent learning: students' perspectives and experiences. Higher Education Academy. URL https://www.heacademy.ac.uk/knowledgehub/independentlearning-student-perspectives-and-experiences.

Tytler, R. (1992). Independent research projects in school science: case studies of autonomous behaviour. International Journal of Science Education, 14(4), 393-411.

Van Valen, L. (1973). A new evolutionary law. Evolutionary Theory, 1, 1-30.

Vancouver, J. B., \& Kendall, L. N. (2006). When self-efficacy negatively relates to motivation and performance in a learning context. Journal of Applied Psychology, 91(5), 1146.

Vansteenkiste, M., Zhou, M., Lens, W., \& Soenens, B. (2005). Experiences of autonomy and control among Chinese learners: vitalizing or immobilizing? Journal of Educational Psychology, 97(3), 468.

Willison, J., Sabir, F., \& Thomas, J. (2016). Shifting dimensions of autonomy in students' research and employment. Higher Education Research \& Development, 1-14. URL http://www.tandfonline. com/doi/abs/10.1080/07294360.2016.1178216.

Yang, N. D. (1998). Exploring a new role for teachers: promoting learner autonomy. System, 26(1), 127-135.

Yeo, G. B., \& Neal, A. (2006). An examination of the dynamic relationship between self-efficacy and performance across levels of analysis and levels of specificity. Journal of Applied Psychology, 91(5), 1088.

Zuur, A. F., Ieno, E. N., \& Elphick, C. S. (2010). A protocol for data exploration to avoid common statistical problems. Methods in Ecology and Evolution, 1(1), 3-14. 